OPEN ACCESS

Edited by:

Guilherme Zweig Rocha,

State University of Campinas, Brazil

Reviewed by:

Weijun Huang,

Shanghai Jiao Tong University

Affiliated Sixth People's

Hospital, China

Jianping Ye,

Zhengzhou University, China

${ }^{*}$ Correspondence:

Nader Lessan

nlessan@icldc.ae

${ }^{\dagger}$ These authors have contributed equally to this work and share first authorship

Specialty section: This article was submitted to Obesity,

a section of the journa

Frontiers in Endocrinology

Received: 10 October 2021 Accepted: 16 November 2021

Published: 13 January 2022

Citation:

Fojas EGF, Radha SK, Ali T, Nadler EP and Lessan N (2022) Weight and Glycemic Control Outcomes of Bariatric Surgery and Pharmacotherapy in Patients With Melanocortin-4 Receptor Deficiency.

Front. Endocrinol. 12:792354. doi: 10.3389/fendo.2021.792354

\section{Weight and Glycemic Control Outcomes of Bariatric Surgery and Pharmacotherapy in Patients With Melanocortin-4 Receptor Deficiency}

\author{
Esphie Grace Fodra Fojas ${ }^{1 \dagger}$, Saradalekshmi Koramannil Radha ${ }^{1 \dagger}$, Tomader Ali ${ }^{1}$, \\ Evan P. Nadler ${ }^{2}$ and Nader Lessan ${ }^{1 *}$ \\ ${ }^{1}$ Research Institute, Imperial College London Diabetes Centre, Abu Dhabi, United Arab Emirates, ${ }^{2}$ Division of Pediatric \\ Surgery, Children's National Hospital, Washington, DC, United States
}

Background: Melanocortin-4 receptor (MC4R) mutations are the most common of the rare monogenic forms of obesity. However, the efficacy of bariatric surgery (BS) and pharmacotherapy on weight and glycemic control in individuals with MC4R deficiency (MC4R-d) is not well-established. We investigated and compared the outcomes of BS and pharmacotherapy in patients with and without MC4R-d.

Methods: Pertinent details were derived from the electronic database among identified patients who had BS with MC4R-d (study group, SG) and wild-type controls (age- and sex-matched control group, CG). Short- and long-term outcomes were reported for the SG. Short-term outcomes were compared between the two groups.

Results: Seventy patients were screened for MC4R-d. The SG [six individuals (four females, two males); 18 (10-27) years old at BS; $50.3(41.8-61.9) \mathrm{kg} / \mathrm{m}^{2}$ at BS, three patients with homozygous T162I mutations, two patients with heterozygous T162I mutations, and one patient with heterozygous I170V mutation] had a follow-up duration of up to 10 years. Weight loss, which varied depending on mutation type [17.99 (6.10-22.54) \%] was stable for 6 months; heterogeneity of results was observed thereafter. BS was found superior to liraglutide on weight and glycemic control outcomes. At a median follow-up of 6 months, no significant difference was observed on weight loss (20.8\% vs. $23.0 \%, p=0.65)$ between the SG and the CG [eight individuals (four females, four males); 19.0 (17.8-36.8) years old at BS, $46.2(42.0-48.3) \mathrm{kg} / \mathrm{m}^{2}$ at BS or phamacotherapeutic intervention]. Glycemic control in patients with MC4R-d and Type 2 diabetes improved post-BS.

Conclusion: Our data indicate efficacious short-term but varied long-term weight loss and glycemic control outcomes of BS on patients with MC4R-d, suggesting the importance of ongoing monitoring and complementary therapeutic interventions.

Keywords: bariatric surgery, MC4R deficiency, monogenic obesity, obesity treatment, obesity pharmacotherapy, metabolic surgery 


\section{INTRODUCTION}

Obesity etiology is complex with interplay between genetic and environmental factors. Early twin studies indicate that 40\%-70\% of obesity is hereditary (1). "Simple obesity" is mostly a polygenic disorder. However, several, albeit rare, monogenic forms are recognized. The commonly reported genetic dysregulations include mutations in the leptin and receptor (LEP/LEPR), proopiomelanocortin $(P O M C)$, proprotein convertase subtilisin/kexin type 1 (PCSK1) and melanocortin-4 receptor $(M C 4 R)$ genes $(2,3)$.

Of those genes, the most common monogenic mutation with a prevalence of up to $6 \%$ have been reported to be alterations in the MC4R alleles (4-6). Melanocortin-4 receptor (MC4R) is an integral part of the leptin-melanocortin pathway, which is responsible for central energy homeostasis and body weight regulation (7). MC4R is a transmembrane G-protein-coupled receptor expressed in the hypothalamic neurons and follows an autosomal dominant mode of inheritance. Phenotypic characteristics in individuals with homozygous and also heterozygous MC4R mutation include excessive hunger and hyperphagia, which is the main driver of the significant and rapid weight gain $(8,9)$. As this is a genetic effect, it carries a substantial behavioral impact, especially in feeding and satiety $(10,11)$. In the UK, a recent study has estimated the frequency of heterozygous MC4R loss-of-function mutations at $0.30 \%$, a considerably higher rate compared to previous approximations (12).

Treatment of obesity, in general, is a major challenge. Lifestyle interventions and pharmacotherapy may lead to some weight loss, but relapse is common $(13,14)$. Bariatric surgery (BS) is currently the most efficacious treatment for obesity with good short-term and long-term outcomes (15). However even when BS is part of the treatment algorithm for cases of "simple obesity", there is risk of weight regain in the long term (16).

Treatment of monogenic obesity (MO) may be even more challenging as $\mathrm{MO}$ is rare, and data on efficacy of different interventions are also sparse. Failure to lose sufficient weight or weight regain may be more common in patients with $\mathrm{MO}$ as their biological drive to eat may be unaffected by the standard interventions, including BS. Previous studies published in 2011 and 2014 suggest that patients with heterozygosity of the MC4R gene can be treated effectively in the short term with BS, but the longer-term success rates are not well described $(17,18)$. Similar observation in a patient with homozygous MC4R deficiency (MC4R-d) was reported in 2015 (19). A systematic review in 2021 synthesized outcomes of BS among patients with monogenic forms of obesity and found that weight loss results were inconsistent for patients with MC4R-d (20). Our group has previously reported short-term effects of BS in three patients with homozygous MC4R mutations, the youngest of whom was only 4 years old when a laparoscopic vertical sleeve gastrectomy (LSG) was performed (21). Here, we report longer-term BS efficacy results up to 10 years in these patients with homozygous $M C 4 R$ mutation with a novel report on revisional BS long-term outcomes in a sibling pair. Three additional cases of heterozygous $M C 4 R$ mutations are presented, and pharmacotherapeutic outcomes are also discussed.

\section{MATERIALS AND METHODS}

Patients who have had genetic screening were identified from the Imperial College London Diabetes Centre (ICLDC) electronic database. Genetic screening is performed in patients suspected to have a genetic component for obesity such as morbid obesity and strong family history. MC4R mutations were screened through either targeted sequencing for $M C 4 R$ gene, whole exome sequencing, or Diabetes-Obesity New Generation Sequencing panel. Patients who tested positive for MC4R-d (study group, SG) and age- and sex-matched individuals with normal MC4R genotype (control group, CG) were identified based on the reported results from the genetic screening. The study flow diagram is presented in Figure 1.

Case history and pertinent details such as age, weight, and HbA1c before and after BS and pharmacotherapy were derived from electronic medical records. Weight was measured and recorded as part of vitals assessment. HbAlc test was performed in the in-house laboratory. Medication compliance was assessed based on physicians' or clinic notes. Patients' glycemic control was managed at ICDLC. BS was performed in different centers locally and abroad. For patients who had multiple or revisional BS, the last surgery was used for pertinent analyses. Data were analyzed and presented as median (interquartile range-IQR).

Written informed consent for using medical data for research purpose in an anonymized form was obtained from all participants at the time of first visit. The study was approved by the Research Ethics Committee at ICLDC and followed the Declaration of Helsinki, 1996.

\section{RESULTS}

Genetic screening for MC4R mutation(s) was performed on 70 ICLDC patients between 2010 and 2020. Twenty-one patients were tested positive to have a mutation in $M C 4 R$ gene. Three mutations were identified: c.485C > T (T162I), 508A > G (I170V), and $307 \mathrm{G}>\mathrm{A}$ (V103I). Six individuals composed the SG [four females, two males; 18 (10-27) years old at BS; 50.3 (41.8-61.9) $\mathrm{kg} / \mathrm{m}^{2}$ at BS; three patients with homozygous T162I mutations, two patients with heterozygous T162I mutations, and one patient with heterozygous I170V mutation]. Eight individuals composed the CG [four females, four males; 19.0 (17.8-36.8) years old at BS, $46.2(42.0-48.3) \mathrm{kg} / \mathrm{m}^{2}$ at BS or phamacotherapeutic intervention]. All patients are Emirati.

\section{Patients With MC4R-d: Presentation of Cases}

Patient 1 (P1) was born full term normal delivery (FTND) with a birthweight of $3.5 \mathrm{~kg}$ to non-consanguineous parents. He started gaining weight around 3 years of age. He weighed $143 \mathrm{~kg}$ (BMI $52 \mathrm{~kg} / \mathrm{m}^{2}$; $>99^{\text {th }}$ percentile) at the age of 12 years. He underwent LSG in another center in the UAE before a genetic diagnosis in our clinic was made. He lost $18 \mathrm{~kg}$ in 6 months and his glycemic control improved (HbAlc 6.1\%, off metformin). He started to regain his lost weight, reaching a weight of $177 \mathrm{~kg}$ (BMI $60 \mathrm{~kg} / \mathrm{m}^{2}$ ) by 6 years post-surgery. A second operation, RYGB 




FIGURE 1 | Flowchart of study population: an overview of patient selection. MC4R, melanocortin-4 receptor; BS, bariatric surgery; PI, pharmacological intervention; SG, study group; CG, control group.

was performed at 18 years of age. He lost $15 \mathrm{~kg}$ (BMI $55 \mathrm{~kg} / \mathrm{m}^{2}$ ) in 1 year and had an HbAlc of $5.6 \%$ off metformin. In the recent 2 years, he was able to maintain good glycemic control (mean HbA1c 5.5\%; range 5.4\%-5.7\%). However, his weight fluctuated; mean BMI was $52.7 \mathrm{~kg} / \mathrm{m}^{2}$ (range $50.0-56.8 \mathrm{~kg} / \mathrm{m}^{2}$ ). Genetic diagnosis was available some months after the operation and showed him to be homozygous for the missense mutation T162I in the MC4R allele.

Patient 2 (P2) is the older sister of P1. She was also born FTND with a birth weight of $3.5 \mathrm{~kg}$. She started gaining weight quite early, around the age of 1 year. She weighed $150 \mathrm{~kg}$ (BMI 60 $\mathrm{kg} / \mathrm{m}^{2} ;>99^{\text {th }}$ percentile) at the age of 14 ; glycemic control was poor with an $\mathrm{HbA1c}$ of $9.7 \%$. She underwent LSG, also prior to genetic diagnosis. She lost $22 \mathrm{~kg}$ (BMI $53 \mathrm{~kg} / \mathrm{m}^{2}$ ) in 6 months. Her weight was consistently lower postoperatively with slight fluctuations near $130 \mathrm{~kg}$, but her $\mathrm{HbAlc}$ varied widely. She underwent a second operation, RYGB, at the age of 20 years. She lost $9 \mathrm{~kg}$ (BMI $47 \mathrm{~kg} / \mathrm{m}^{2}$ ) by 3 months post-RYGB and maintained her weight loss up to 2 years later; glycemic control did improve, but remained inadequate (HbA1c 7.4\%). In the subsequent 2 years, there were slight variations in her BMI (mean 46.0; range $43.8-48.2 \mathrm{~kg} / \mathrm{m}^{2}$ ) and wider fluctuations in her glycemic control (mean 8.4\%; range 6.9\%-9.6\%). Most recently, she has been on a diet program and has managed to lose $13 \mathrm{~kg}$ in weight, with good improvement in her glycemic control (HbAlc dropping from $9.0 \%$ to $5.2 \%$ ) in a matter of 2 months. She is currently on vidagliptin + metformin. Genetic test results available after LSG have also shown a genotype of MC4R-/with the missense mutation T162I.

Patient 3 (P3) was born full term to consanguineous Emirati parents (second cousins). Weight gain and obesity started at 6 months of age. At the age of 10 months, she was unable to sit normally and was hospitalized to help manage her excessive weight. She had acanthosis nigricans, impaired fasting glycemia, elevated fasting insulin, and HOMA-IR. Other features of note were severe vitamin $\mathrm{D}$ deficiency, hypertension, and obstructive sleep apnoea (OSA). At the age of 4, she weighed $67.8 \mathrm{~kg}$ (BMI 44 $\mathrm{kg} / \mathrm{m}^{2}$ ). She had a full assessment including a review of management options by the Hospital Ethics Committee and underwent LSG in the United States. Four months post-surgery, her BMI was 9 points lower; she had normal fasting glucose, HbA1c, vitamin D, and cortisol. She lost over $13 \mathrm{~kg}$ (BMI $33 \mathrm{~kg} /$ $\mathrm{m}^{2}$ ) 9 months after sleeve gastrectomy. However, she subsequently gained $2 \mathrm{~kg}$ within 2 months. By year 4 postoperatively, her BMI was $35.8 \mathrm{~kg} / \mathrm{m}^{2}$ with an $\mathrm{HbA} 1 \mathrm{c}$ of $6.0 \%$. One year later (5 years after her surgery), her BMI was 39.3 kg/ $\mathrm{m}^{2}$, close to her pre-operative BMI; HbA1c was $6.3 \%$ and she was prescribed metformin. At 6.5 years post-BS, her BMI is $42.1 \mathrm{~kg} /$ $\mathrm{m}^{2}$. Her genetic testing (done at age 4) showed her to be homozygous for an MC4R mutation (T162I). P3 has a younger brother with the same $M C 4 R$ mutation who recently had BS at 5 years of age and presented with non-alcoholic steatohepatitis (stage 3-4), a condition not previously seen in P3. P3 also has two other siblings with $M C 4 R$ null genotype and rare ACBD5 mutation, which affects peroxisomal oxidation of very long chain fatty acids.

Patient 4 (P4), aunt of P3, started to become overweight at age 15 years. She had impaired fasting glucose (IFG) with normal HbA1c levels. Other history of relevance included a strong familial history of diabetes and hyperlipidemia. She was able to lose $20 \mathrm{~kg}$ of weight through diet but regained this same amount. At age 33 years, she was severely obese (weight $114 \mathrm{~kg}$, BMI 
$\left.49 \mathrm{~kg} / \mathrm{m}^{2}\right)$. She underwent sleeve gastrectomy and had lost $20 \mathrm{~kg}$ (BMI $40 \mathrm{~kg} / \mathrm{m}^{2}$ ) in 4 months. Over a year after surgery, her BMI was $32.9 \mathrm{~kg} / \mathrm{m}^{2}$ (total weight loss of approximately $27 \mathrm{~kg}$ ) and her HbA1c was $5.4 \%$. Two years post-BS, her BMI increased to 36.1 $\mathrm{kg} / \mathrm{m}^{2}$ and her HbAlc was slightly lower at $5.1 \%$. Genetic testing (performed and available before surgery) revealed that she was heterozygous for T162I mutation in the MC4R gene.

Patient 5 (P5), the sister of P4, was seen in our clinic at the age of 21 years. At the time, she weighed $181 \mathrm{~kg}$ (BMI $71 \mathrm{~kg} / \mathrm{m}^{2}$ ). Comorbidities included hypothyroidism, IFG and impaired glucose tolerance (IGT), dyslipidemia, fatty liver, OSA, hypertension, and deficiencies in vitamin B12 and D. A trial of dietetic intervention and medical treatment with liraglutide, with a target BMI of lower than $60 \mathrm{~kg} / \mathrm{m}^{2}$ were unfortunately unsuccessful. She proceeded with sleeve gastrectomy (pre-BS BMI $68 \mathrm{~kg} / \mathrm{m}^{2}$ ) at the age of 24 years and had a drastic weight loss of $18 \mathrm{~kg}$ (BMI $\left.60 \mathrm{~kg} / \mathrm{m}^{2}\right)$ in 1.5 months, with a further $16 \mathrm{~kg}$ (BMI $54 \mathrm{~kg} / \mathrm{m}^{2}$ ) weight loss in the subsequent 2 months and a reduction in her $\mathrm{HbA1c}$ to $4.9 \%$. She is currently on vitamins B12 and D3, iron, and thyroxine supplementation. Genetic testing (done pre-operatively) showed her to be heterozygous for T162I MC4R mutation.

Patient 6 (P6) is a 16-year-old male with a strong family history of diabetes who first came to the center for pediatric obesity management. He was noted to have acanthosis, and by age 17, he developed Type 2 diabetes (T2D). He had poor glycemic control, at least in part due to non-compliance to medication. $\mathrm{He}$ was also hypertensive, and had hypertriglyceridemia, proteinuria, hyperuricemia, and joint pain. By age 23, he weighed $110 \mathrm{~kg}$ (BMI $35 \mathrm{~kg} / \mathrm{m}^{2}$ ) and had an HbAlc of $9.6 \%$. He underwent sleeve gastrectomy and lost $23 \mathrm{~kg}\left(\mathrm{BMI} 28 \mathrm{~kg} / \mathrm{m}^{2}\right)$ in 7 months with excellent glycemic control on metformin only. He is recently off metformin, has normal blood pressure, and is taking vitamin D3, multivitamins, and vitamin B12. MC4R sequencing revealed heterozygosity with variant $\mathrm{I} 170 \mathrm{~V}$, a missense alteration.

\section{Weight Loss and Glycemic Control Outcomes Bariatric Surgery}

Patient characteristics and response to BS are summarized in Table 1. Genetic testing revealed two MC4R genotypes [five (83.3\%) T162I, one (16.7\%) I170V] in our cohort. LSG was the
BS performed for all patients, with two siblings (P1 and P2) who had RYGB as revisional BS procedures.

For all six patients, stable weight loss was observed up to at least 6 months (Figure 2), supporting our former observation that MC4R may not be essential for short-term weight loss postBS. However, our data indicate heterogeneity in response to LSG after 6 months: one patient had continued net weight loss for over 5 years (P2); two patients (P3, P4) continued to lose weight for several months with slight increases observed subsequently; while one patient $(\mathrm{P} 1)$ regained his initial weight after over a year, with further weight gain until 6.5 years when he had a revisional RYGB procedure. Outcomes for P1 and P2, who are siblings with the same mutation and second BS (Roux-en-Y gastric bypass), were very different.

Glycemic control outcomes of the patients after BS are also dissimilar (Figure 3). Although P1 has increasingly gained weight post-LSG, his $\mathrm{HbA1c}$ levels have lessened and were consistently lower than his pre-surgery HbAlc. In contrast, his sister, P2, who had significant weight reduction post-LSG and RYGB has not seen improvement in her glycemic control; her HbA1c levels were widely fluctuating and were at times much higher than her pre-operative values. Interestingly, her recent diet program (self-reported as composed of low-calorie diet, calorie counting, and no addition of sugar whether white, brown, or artificial sweetener) made her lose $13 \mathrm{~kg}$ in less than 3 months, leading to a drastic drop in her HbAlc (from 9.0\% to 5.2\%). Similar trends were observed for P3 who had a slight increase in HbA1c and a modest weight gain, and P6 who had weight loss and a net reduction in $\mathrm{HbA} 1 \mathrm{c}$ levels. Slight variations in glycemic control were observed with considerable weight loss for P4 and P5 who are sisters.

\section{Pharmacotherapy}

Our limited data (Table 2) indicate apparent lack of efficacy of liraglutide (1.8 mg OD) in homozygous T162I mutation in shortterm use; weight gain and increased $\mathrm{HbA1c}$ level were observed in the female patient P2 after 3 months of treatment. In contrast, 14 months use of liraglutide (3.0 mg OD) did benefit patient P5 (heterozygous T162I deficit) with a weight loss of 5.6\% (from 179 $\mathrm{kg}$ to $169 \mathrm{~kg}$ ) and a $7.4 \%$ improvement (from $5.4 \%$ to $5.0 \%$ HbA1c) in glycemic control. Short-term (3 months) use of

TABLE 1 | Patient characteristics and response to bariatric surgery procedures in patients with MC4R deficiency.

\begin{tabular}{|c|c|c|c|c|c|c|c|c|}
\hline Patient & \multicolumn{2}{|c|}{ P1 } & \multicolumn{2}{|c|}{ P2 } & P3 & P4 & P5 & P6 \\
\hline Sex & \multicolumn{2}{|c|}{ Male } & \multicolumn{2}{|c|}{ Female } & Female & Female & Female & Male \\
\hline Zygosity & \multicolumn{2}{|c|}{ Homozygous } & \multicolumn{2}{|c|}{ Homozygous } & Homozygous & Heterozygous & Heterozygous & Heterozygous \\
\hline Variant & \multicolumn{2}{|c|}{ T162I } & \multicolumn{2}{|c|}{ T162I } & T162I & T162I & T162I & I170V \\
\hline Type of surgery & LSG & RYGB & LSG & RYGB & LSG & LSG & LSG & LSG \\
\hline Age (years) at surgery & 12 & 18 & 14 & 20 & 4 & 33 & 25 & 22 \\
\hline Weight (kg) before LSG & 143 & 177 & 150 & 130 & 67.8 & 114 & 171 & 110 \\
\hline BMI $\left(\mathrm{kg} / \mathrm{m}^{2}\right)$ before LSG & 52.0 & 60.5 & 60.0 & 50.3 & 44.0 & 49.0 & 67.6 & 35.0 \\
\hline Lowest weight (kg) after LSG & 125 & 149 & 124 & 112 & 54.5 & 77 & 137.2 & 88.1 \\
\hline Lowest BMI $\left(\mathrm{kg} / \mathrm{m}^{2}\right)$ after LSG & 45.4 & 50.7 & 48.6 & 43.8 & 33.3 & 32.9 & 53.6 & 28.1 \\
\hline$\%$ Weight loss & 12.6 & 15.8 & 17.0 & 13.8 & 19.6 & 32.5 & 19.8 & 19.9 \\
\hline HbA1c (\%) before LSG & 8.1 & 6.1 & NA & 8.0 & NA & NA & 5 & 9.6 \\
\hline HbA1c (\%) after LSG & $5.6-6.6$ & $5.4-5.9$ & $6.5-11.4$ & $6.8-9.6$ & $5.5-6.3$ & $4.8-5.4$ & 4.9 & $5.7-8.3$ \\
\hline
\end{tabular}

LSG, laparoscopic sleeve gastrectomy; RYGB, Roux-en-Y gastric bypass; BMI, body mass index; MC4R, melanocortin-4 receptor; NA, not available. 


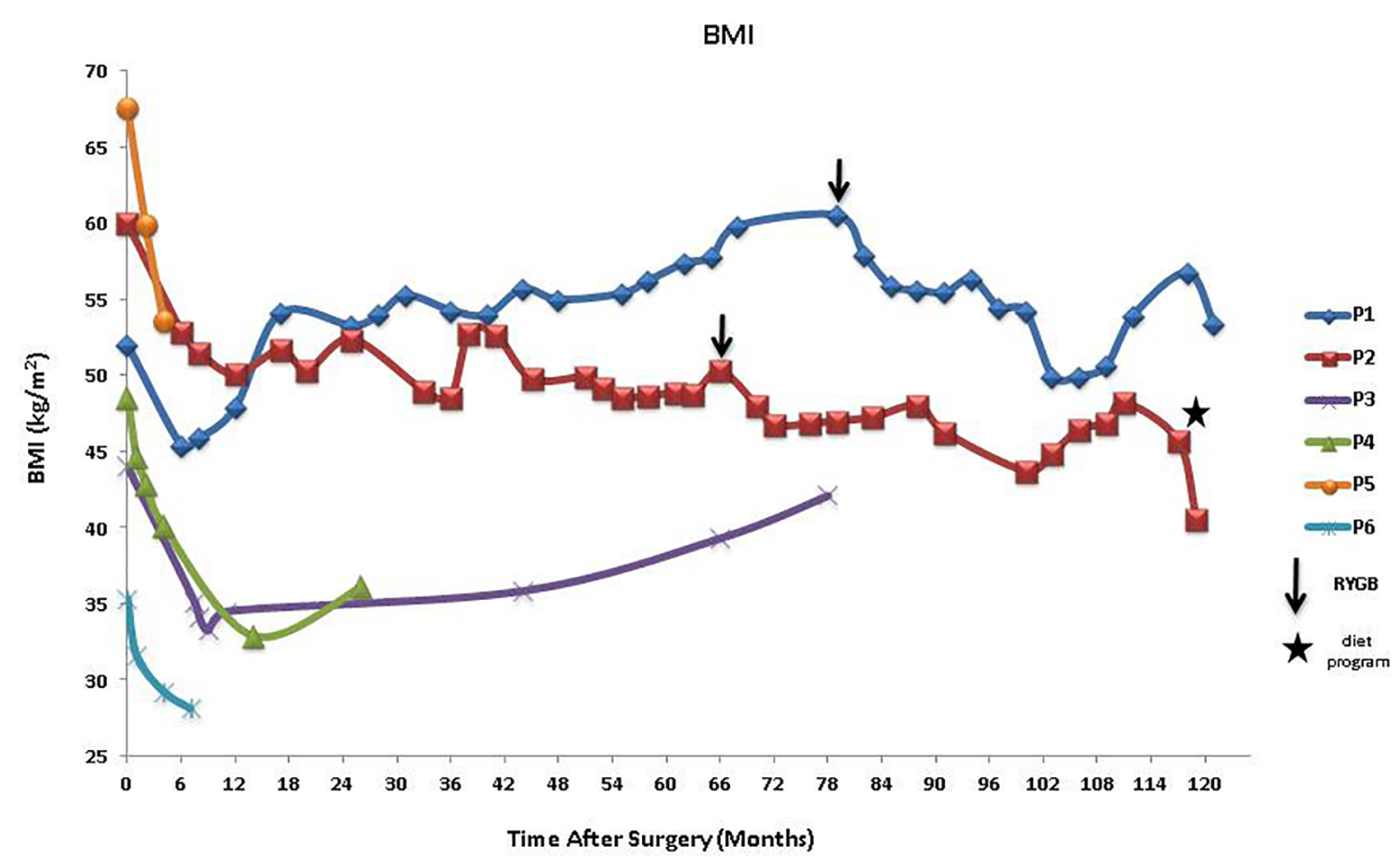

FIGURE 2 | BMI after LSG in patients with MC4R deficiency showing other interventions, RYGB, and diet program. BMI, body mass index; LSG, laparoscopic sleeve gastrectomy; RYGB, Roux-en-Y gastric bypass; MC4R, melanocortin-4 receptor.

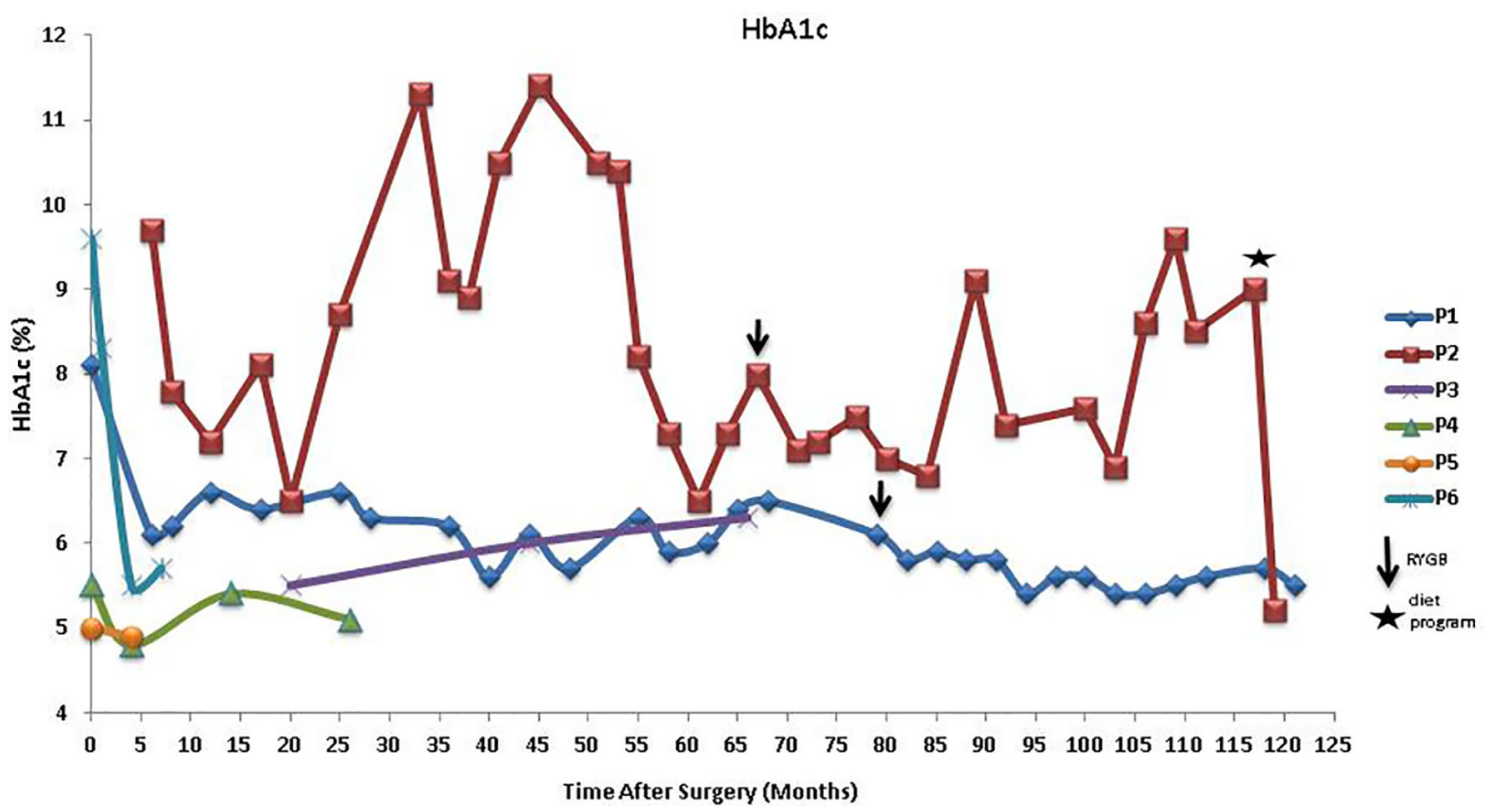

FIGURE 3 | HbA1c after LSG in patients with MC4R deficiency showing other interventions, RYGB, and diet program. LSG, laparoscopic sleeve gastrectomy; RYGB, Roux-en-Y gastric bypass; MC4R, melanocortin-4 receptor. 
TABLE 2 | Patient characteristics and response to pharmacotherapy in patients with MC4R deficiency.

\begin{tabular}{|c|c|}
\hline Patient Characteristics & Before BS \\
\hline \multicolumn{2}{|l|}{ P2* } \\
\hline Pharmacotherapy & Liraglutide \\
\hline Dose & $1.8 \mathrm{mg} \mathrm{OD}$ \\
\hline Age (years) at prescription ( $\mathrm{Rx}$ ) & 19 \\
\hline Weight $(\mathrm{kg})$ before $\mathrm{Rx}$ & 125 \\
\hline BMI $\left(\mathrm{kg} / \mathrm{m}^{2}\right)$ before $\mathrm{Rx}$ & 48.8 \\
\hline Treatment duration (months) & 3 \\
\hline Lowest weight $(\mathrm{kg})$ after $\mathrm{Rx}$ & 129 \\
\hline Lowest BMl $\left(\mathrm{kg} / \mathrm{m}^{2}\right)$ after $\mathrm{Rx}$ & 50.3 \\
\hline$\%$ Weight loss & $-3.1 \%$ \\
\hline HbA1c (\%) before Rx & 7.3 \\
\hline HbA1c (\%) after Rx & 8.0 \\
\hline \multicolumn{2}{|l|}{ P5 } \\
\hline Pharmacotherapy & Liraglutide \\
\hline Dose & $3.0 \mathrm{mg} O D$ \\
\hline Age (years) at prescription ( $\mathrm{Rx})$ & 22 \\
\hline Weight $(\mathrm{kg})$ before $\mathrm{Rx}$ & 179 \\
\hline BMl $\left(\mathrm{kg} / \mathrm{m}^{2}\right)$ before $\mathrm{Rx}$ & 70 \\
\hline Treatment duration (months) & 14 \\
\hline Lowest weight $(\mathrm{kg})$ after $\mathrm{Rx}$ & 169 \\
\hline Lowest BMI $\left(\mathrm{kg} / \mathrm{m}^{2}\right)$ after $\mathrm{Rx}$ & 66 \\
\hline$\%$ Weight loss & 5.6 \\
\hline $\mathrm{HbA1c}(\%)$ before $\mathrm{Rx}$ & 5.4 \\
\hline HbA1c (\%) after Rx & $5.0-5.1$ \\
\hline \multicolumn{2}{|l|}{ P6 } \\
\hline Pharmacotherapy & Orlistat \\
\hline Dose & $120 \mathrm{mg}$ TID \\
\hline Age (years) at prescription ( $\mathrm{Rx})$ & 21 \\
\hline Weight $(\mathrm{kg})$ before $\mathrm{Rx}$ & 110 \\
\hline BMl $\left(\mathrm{kg} / \mathrm{m}^{2}\right)$ before $\mathrm{Rx}$ & 35.1 \\
\hline Treatment duration (months) & 3 \\
\hline Lowest weight $(\mathrm{kg})$ after $\mathrm{Rx}$ & 112 \\
\hline Lowest BMI $\left(\mathrm{kg} / \mathrm{m}^{2}\right)$ after $\mathrm{Rx}$ & 35.9 \\
\hline$\%$ Weight loss & $-1.8 \%$ \\
\hline HbA1c (\%) before Rx & 9.6 \\
\hline HbA1c (\%) after Rx & 10.2 \\
\hline
\end{tabular}

orlistat (120 mg TID) did not benefit patient P6 (heterozygous I170V) in both weight loss and glycemic control as the patient, in fact, had small weight and HbAlc increase.
Patients P2, P5, and P6 were 19, 22, and 22 years of age, respectively, when they started the treatments. Patient P2 was treated with liraglutide after LSG due to weight regain. However, due to unsatisfactory outcomes, revisional BS, RYGB, was performed. Both patients P5 and P6 who were treated with liraglutide and orlistat, respectively, were tried on these pharmacotherapeutic interventions prior to LSG. Overall, BS was found superior to liraglutide and orlistat for both weight loss and glycemic control outcomes.

\section{Weight Loss and Glycemic Control Comparison in Individuals With and Without MC4R-d}

Weight loss percentage and glycemic control lowering at a median of 6 months post-intervention were compared between age- and sex-matched MC4R-deficient and wild-type controls (Table 3).

Weight loss at median 6 months post BS was not significantly different between patients with and without MC4R-d $(p=0.65)$. However, the weight loss post BS in patients with MC4R-d showed variation depending on the type of mutation [17.99 (6.1-22.54) \%]. Homozygous T162I did not benefit from BS in terms of weight loss compared to their age- and sex- matched controls. Heterozygous T162I and heterozygous I170V benefited similarly from BS compared to the controls. Response to liraglutide treatment was comparable in MC4R T162I heterozygous patient and control. Outcomes of orlistat use was inconsistent: patient heterozygous for I170V mutation had a marginal weight gain, while age- and sex-matched wild type had over 10\% excess body weight loss; homozygous T162I did not benefit and had small weight gain as much as the control. Weight loss comparison following surgical and pharmacological interventions at median 6 months between the study and control groups is shown in Figure 4.

Glycemic control outcomes after sleeve gastrectomy in two MC4R-deficient patients (heterozygous I170V and homozygous T162I) who both had T2D were substantial compared to their non-diabetic controls. On liraglutide use, the patient with heterozygous T162I had similar HbAlc lowering with his ageand sex-matched control ( $0.4 \%$ vs. $0.3 \%)$.

TABLE 3 | Weight loss and glycemic control comparison following surgical and pharmacological interventions at median 6 months between age- and sex-matched individuals with and without MC4R-deficiency.

\begin{tabular}{|c|c|c|c|c|c|c|c|c|}
\hline $\begin{array}{l}\text { Type of } \\
\text { intervention }\end{array}$ & $\begin{array}{l}\text { Age (MC4R-deficient vs. MC4R wild } \\
\text { type }\end{array}$ & Sex & Mutation & Zygosity & \multicolumn{2}{|c|}{ Weight loss \% } & \multicolumn{2}{|c|}{ HbA1c \% lowering } \\
\hline & $23 / 18$ & M & I170V & Heterozygous & 22.54 & 29.9 & 3.9 & 0.2 \\
\hline & $18 / 17.8$ & M & T162l & Homozygous & 8.08 & 35.27 & 2 & 0.3 \\
\hline & $14 / 18$ & $\mathrm{~F}$ & T162l & Homozygous & 6.91 & 23.75 & NA & NA \\
\hline Orlistat (120 mg & $20.5 / 19.5$ & M & I170V & Heterozygous & -0.91 & 10.29 & NA & NA \\
\hline TID) & $12 / 14.5$ & M & $\mathrm{T} 162 \mathrm{l}$ & Homozygous & -4.62 & -4.1 & NA & NA \\
\hline
\end{tabular}

MC4R, melanocortin-4 receptor; OD, once daily; TID, three times daily; NA, not available. 




aMCAR deficient घMCAR vild-type

FIGURE 4 | Comparison of weight loss following surgical and pharmacological interventions at median 6 months between age- and sex-matched individuals with and without MC4R-deficiency, as shown in Table 3. MC4R, melanocortin-4 receptor.

\section{DISCUSSION}

The melanocortin system regulates appetite and an intact leptinmelanocortin signaling is required for normal physiological response to calorie restriction (22-24). Lifestyle modification for weight loss is difficult for people with MC4R-d as they are less responsive to diet and exercise. Hence, BS is often considered as the obesity treatment of choice for individuals with MC4R-d. Our previous work has indicated that MC4R signaling may not be needed for short-term response to sleeve gastrectomy, with continuous weight loss observed several months post-BS (21). Here we report the short- and long-term outcomes of BS on weight and glycemic control in Emirati patients with $M C 4 R-d$, including two siblings (male and female) who had a revision of their previous LSG to a RYGB. The mutations reported in our study, both T162I and I170V, are missense mutations and result in partial (T162I) and complete (I170V) loss of function of $M C 4 R$ gene $(25,26)$. A recent article reported long-term weight loss outcome on bi-allelic mutation in the $M C 4 R$ gene in a patient who underwent sleeve gastrectomy only (27). The recent systematic review reported that most of the studies on outcomes of BS in MC4R mutation found no association of MC4R mutations with weight loss (20). We are reporting, for the first time to our knowledge, long-term outcomes of revisional surgery (RYGB) in both sexes with the $M C 4 R$ null genotype. Our results suggest that longer-term response may be determined by factors other than MC4R genotype. These factors may include sex and gut microbiome as well as other environmental factors, as may be the case in patients with "simple obesity" (28-30).

Although the role of genetics in the case of P1 and P2 cannot be delineated, how mutation type and zygosity affect BS outcomes in these patients has been observed. Weight loss 6 months post-BS was not significantly different among patients without and with heterozygous MC4R-d, suggesting that in terms of weight reduction, patients with heterozygous T162I and $1170 \mathrm{~V}$ mutations may benefit from BS as much as MC4R-normal individuals, a finding similar to a previous report (17). Another recent study has reported no significant weight loss on a patient with compound heterozygous mutation (c.105C >A; p.Y35X, c.110A > T; p.D37V) (27). Individuals with homozygous T1621 mutation in $M C 4 R$ and those with compound heterozygous MC4R-d might require multiple surgeries or continued pharmacological intervention to maintain weight loss over a longer period of time. It is also noteworthy that our younger patient had a more favorable outcome in terms of weight loss, suggesting that earlier intervention in homozygous T162I is more likely to be beneficial; increasing BMI from 12 months post-BS warrant longer-term monitoring. On glycemic control, mutation type and zygosity do not appear to influence the outcomes suggesting the significance and interplay of other factors $(31,32)$. Adherence to a strict diet as in the case of P2 may be required for best glycemic control regardless of BS (33). The lack of diet information on the other patients as well as physical activity profile of the cohort including the control group is a 
limitation of the study, which may be addressed in prospective studies.

With liraglutide treatment, we have observed that response was comparable in patients with heterozygous T1621 mutation in MC4R and controls (34). Liraglutide treatment for 16 weeks has been reported to result in comparable weight loss and decrease in HbA1c in patients with MC4R-d and controls (35, 36). However, the difference in \% weight loss of BS compared to liraglutide use on individuals with heterozygous T162I may still be vast (14.2\% for P5). Again, the outcome of P2's diet program on her weight and glycemic control underscores the importance of diet and lifestyle modification on MC4R deficits, in addition to pharmacotherapeutic course of treatment and BS. The effect of dietary and lifestyle interventions may depend on the type of mutation (37). An additional finding here is that short-term orlistat treatment did not seem to have any beneficial effects on weight loss or glycemic control for our patient with heterozygous I170V mutation.

In conclusion, we have described here outcomes of BS with or without selected pharmacotherapy in a cohort of patients with heterozygous and homozygous MC4R mutations. Our data indicate beneficial but varied long-term effects of BS on these patients, which suggests that life-long monitoring and additional therapies including adjunct pharmacotherapy and revisional BS should be considered. Further elucidation of the mechanisms behind these results requires a larger cohort of patients in multicenter studies.

\section{REFERENCES}

1. Maes HH, Neale MC, Eaves LJ. Genetic and Environmental Factors in Relative Body Weight and Human Adiposity. Behav Genet (1997) 27 (4):325-51. doi: 10.1023/A:1025635913927

2. Fairbrother U, Kidd E, Malagamuwa T, Walley A. Genetics of Severe Obesity. Curr Diabetes Rep (2018) 18(10):85. doi: 10.1007/s11892-018-1053-x

3. Thaker VV. Genetic and Epigenetic Causes of Obesity. Adolesc Med State Art Rev (2017) 28(2):379-405. doi: 10.1542/9781581109405-genetic

4. Micioni Di Bonaventura E, Botticelli L, Tomassoni D, Tayebati SK, Micioni Di Bonaventura MV, Cifani C. The Melanocortin System Behind the Dysfunctional Eating Behaviors. Nutrients (2020) 12(11):3502. doi: 10.3390/ nu12113502

5. Trevellin E, Granzotto M, Host C, Grisan F, De Stefani D, Grinzato A, et al. A Novel Loss of Function Melanocortin-4-Receptor Mutation (MC4RF313Sfs*29) in Morbid Obesity. J Clin Endocrinol Metab (2020) 106 (3):736-49. doi: 10.1210/clinem/dgaa885

6. Lubrano-Ubrano-Berthelier C, Cavazos M, Dubern B, Shapiro A, Le Stunff C, Zhang S, et al. Molecular Genetics of Human Obesity-Associated MC4R Mutations. Ann NY Acad Sci (2003) 994(1):49-57. doi: 10.1111/j.17496632.2003.tb03161.x

7. Valette M, Bellisle F, Carette C, Poitou C, Dubern B, Paradis G, et al. Eating Behaviour in Obese Patients With Melanocortin-4 Receptor Mutations: A Literature Review. Int J Obes (Lond) (2013) 37(8):1027-35. doi: 10.1038/ijo.2012.169

8. Yeo GS, Lank EJ, Farooqi IS, Keogh J, Challis BG, O’Rahilly S. Mutations in the Human Melanocortin-4 Receptor Gene Associated With Severe Familial Obesity Disrupts Receptor Function Through Multiple Molecular Mechanisms. Hum Mol Genet (2003) 12(5):561-74. doi: 10.1093/hmg/ddg057

9. Farooqi IS, Yeo GS, Keogh JM, Aminian S, Jebb SA, Butler G, et al. Dominant and Recessive Inheritance of Morbid Obesity Associated With Melanocortin 4 Receptor Deficiency. J Clin Invest (2000) 106(2):271-9. doi: 10.1172/JCI9397

10. Grimm ER, Steinle NI. Genetics of Eating Behavior: Established and Emerging Concepts. Nutr Rev (2011) 69(1):52-60. doi: 10.1111/j.1753-4887.2010.00361.x

\section{DATA AVAILABILITY STATEMENT}

The data presented in the study are deposited in the ClinVar repository, accession numbers SCV002014765.1, SCV002014763.1, SCV002014764.1.

\section{ETHICS STATEMENT}

The studies involving human participants were reviewed and approved by the Research Ethics Committee, Imperial College London Diabetes Centre. Written informed consent to participate in this study was provided by the participants and/ or participants' legal guardian/next of kin.

\section{AUTHOR CONTRIBUTIONS}

EF: study design, data acquisition and interpretation, and manuscript writing; SR: data acquisition, statistical analyses and manuscript writing; TA: study design and manuscript writing; EN: manuscript writing; NL: study design, data interpretation, and manuscript writing.

\section{ACKNOWLEDGMENTS}

The authors would like to thank Mubadala Health for supporting this study.

11. Adan RA, Tiesjema B, Hillebrand JJ, la Fleur SE, Kas MJ, de Krom M. The MC4 Receptor and Control of Appetite. Br J Pharmacol (2006) 149(7):815-27. doi: 10.1038/sj.bjp.0706929

12. Wade KH, Lam BYH, Melvin A, Pan W, Corbin LJ, Hughes DA, et al. Loss-ofFunction Mutations in the Melanocortin 4 Receptor in a UK Birth Cohort. Nat Med (2021) 27(6):1088-96. doi: 10.1038/s41591-021-01349-y

13. Gallo S, Cheskin LJ. Treatment of Obesity: Beyond the Diet. Gastroenterol Clin North Am (2021) 50(1):113-25. doi: 10.1016/j.gtc.2020.10.003

14. Tak YJ, Lee SY. Long-Term Efficacy and Safety of Anti-Obesity Treatment: Where Do We Stand? Curr Obes Rep (2021) 10(1):14-30. doi: 10.1007/ s13679-020-00422-w

15. Hossain N, Arhi C, Borg CM. Is Bariatric Surgery Better Than Nonsurgical Weight Loss for Improving Asthma Control? A Systematic Review. Obes Surg (2021) 31(4):1810-32. doi: 10.1007/s11695-021-05255-7

16. Athanasiadis DI, Martin A, Kapsampelis P, Monfared S, Stefanidis D. Factors Associated With Weight Regain Post-Bariatric Surgery: A Systematic Review. Surg Endosc (2021) 35(8):1-16. doi: 10.1007/s00464-021-08329-w

17. Censani M, Conroy R, Deng L, Oberfield SE, McMahon DJ, Zitsman JL, et al. Weight Loss After Bariatric Surgery in Morbidly Obese Adolescents With MC4R Mutations. Obesity (2014) 22(1):225-31. doi: 10.1002/oby.20511

18. Aslan IR, Campos GM, Calton MA, Evans DS, Merriman RB, Vaisse C. Weight Loss After Roux-En-Y Gastric Bypass in Obese Patients Heterozygous for MC4R Mutations. Obes Surg (2011) 21(7):930-4. doi: 10.1007/s11695-010-0295-8

19. Aslan I, Ranadive SA, Ersoy BA, Rogers SJ, Lustig RH, Vaisse C. Bariatric Surgery in a Patient With Complete MC4R Deficiency. Int J Obes (2011) 35 (3):457-61. doi: 10.1038/ijo.2010.168

20. Gupta SR, Zhou Y, Wadden TA, Berkowitz RI, Chao AM. A Systematic Review of Genetic Correlates of Weight Loss After Bariatric Surgery. Obes Surg (2021) 31(10):1-12. doi: 10.1007/s11695-021-05585-6

21. Jelin EB, Daggag H, Speer AL, Hameed N, Lessan N, Barakat M, et al. Melanocortin-4 Receptor Signaling is Not Required for Short-Term Weight Loss After Sleeve Gastrectomy in Pediatric Patients. Int J Obes (Lond) (2016) 40(3):550-3. doi: 10.1038/ijo.2015.230 
22. Sergi D, Williams LM. Potential Relationship Between Dietary Long-Chain Saturated Fatty Acids and Hypothalamic Dysfunction in Obesity. Nutr Rev (2020) 78(4):261-77. doi: 10.4321/s1137-66272012000200010

23. González-Jiménez E, Aguilar Cordero MJ, Padilla López CA, García García I. Monogenic Human Obesity: Role of the Leptin-Melanocortin System in the Regulation of Food Intake and Body Weight in Humans. Anales Del Sistema Sanitario De Navarra (2012) 35(2):285-93. doi: 10.4321/s1137-66272012000200010

24. Farooqi IS. Monogenic Human Obesity. Obes Metab (2008) 36:1-11. doi: $10.1159 / 000115333$

25. Vaisse C, Clement K, Durand E, Hercberg S, Guy-Grand B, Froguel P. Melanocortin-4 Receptor Mutations Are a Frequent and Heterogeneous Cause of Morbid Obesity. J Clin Invest (2000) 106(2):253-62. doi: 10.1172/JCI9238

26. Tan K, Pogozheva ID, Yeo GS, Hadaschik D, Keogh JM, Haskell-Leuvano C, et al. Functional Characterization and Structural Modeling of Obesity Associated Mutations in the Melanocortin 4 Receptor. Endocrinology (2009) 150(1):114-25. doi: 10.1210/en.2008-0721

27. Poitou C, Puder L, Dubern B, Krabusch P, Genser L, Wiegand S, et al. LongTerm Outcomes of Bariatric Surgery in Patients With Bi-Allelic Mutations in the POMC, LEPR, and MC4R Genes. Surg Obes Related Dis (2021) 17 (8):1449-56. doi: 10.1016/j.soard.2021.04.020

28. Mulla CM, Middelbeek RJ, Patti M-E. Mechanisms of Weight Loss and Improved Metabolism Following Bariatric Surgery. Annals NY Acad Sci (2018) 1411(1):53. doi: 10.1111/nyas.13409

29. Gutiérrez-Repiso C, Moreno-Indias I, de Hollanda A, Martín-Núñez GM, Vidal J, Tinahones FJ. Gut Microbiota Specific Signatures Are Related to the Successful Rate of Bariatric Surgery. Am J Transl Res (2019) 11(2):942.

30. Nielsen MS, Christensen BJ, Schmidt JB, Tækker L, Holm L, Lunn S, et al. Predictors of Weight Loss After Bariatric Surgery-A Cross-Disciplinary Approach Combining Physiological, Social, and Psychological Measures. J Intl J Obesity (2020) 44:1-12. doi: 10.1038/s41366-020-0576-9

31. Souteiro P, Belo S, Neves JS, Magalhães D, Silva RB, Oliveira SC, et al. Preoperative Beta Cell Function is Predictive of Diabetes Remission After Bariatric Surgery. Obesity Surgery (2017) 27(2):288-94. doi: 10.1007/s11695-016-2300-3

32. Dang JT, Sheppard C, Kim D, Switzer N, Shi X, Tian C, et al. Predictive Factors for Diabetes Remission After Bariatric Surgery. Canadian J Surg (2019) 62(5):315. doi: 10.1503/cjs.014516
33. Mulla CM, Baloch HM, Hafida S. Management of Diabetes in Patients Undergoing Bariatric Surgery. Current Diabetes Reports (2019) 19(11):1-11. doi: 10.1007/s11892-019-1242-2

34. SK Radha, EG Fojas, T Ali, SG Suliman, N Lessan eds. The Short-Term Effect of Surgical and Pharmacological Intervention in Obesity Caused by MC4R Deficiency: A Single Centre Experience. Endocrine Abstracts. Bioscientifica (2021).

35. Iepsen EW, Zhang J, Thomsen HS, Hansen EL, Hollensted M, Madsbad S, et al. Patients With Obesity Caused by Melanocortin-4 Receptor Mutations can be Treated With a Glucagon-Like Peptide-1 Receptor Agonist. Cell Metab (2018) 28(1):23-32.e3. doi: 10.1016/j.cmet.2018.05.008

36. Iepsen EW, Have CT, Veedfald S, Madsbad S, Holst JJ, Grarup N, et al. GLP-1 Receptor Agonist Treatment in Morbid Obesity and Type 2 Diabetes Due to Pathogenic Homozygous Melanocortin-4 Receptor Mutation: A Case Report. Cell Rep Med (2020) 1(1):100006. doi: 10.1016/j.xcrm.2020.100006

37. Zlatohlavek L, Vrablik M, Motykova E, Ceska R, Vasickova L, Dlouha D, et al. FTO and MC4R Gene Variants Determine BMI Changes in Children After Intensive Lifestyle Intervention. Clin Biochem (2013) 46(4-5):313-6. doi: 10.1016/j.clinbiochem.2012.11.017

Conflict of Interest: The authors declare that the research was conducted in the absence of any commercial or financial relationships that could be construed as a potential conflict of interest.

Publisher's Note: All claims expressed in this article are solely those of the authors and do not necessarily represent those of their affiliated organizations, or those of the publisher, the editors and the reviewers. Any product that may be evaluated in this article, or claim that may be made by its manufacturer, is not guaranteed or endorsed by the publisher.

Copyright (C) 2022 Fojas, Radha, Ali, Nadler and Lessan. This is an open-access article distributed under the terms of the Creative Commons Attribution License (CC BY). The use, distribution or reproduction in other forums is permitted, provided the original author(s) and the copyright owner(s) are credited and that the original publication in this journal is cited, in accordance with accepted academic practice. No use, distribution or reproduction is permitted which does not comply with these terms. 